\title{
Nomear seu universo: Por quê? Como? Alguns exemplos entre as sociedades amazônicas
}

\author{
Françoise Grenand ${ }^{1}$ \\ Tradução: Joana Cabral de Oliveira \\ Revisấ técnica: Luísa Valentini e Nicodème de Renesse
}

A necessidade - e a alegria - de nomear é universalmente difundida. Por toda parte encontramos nomenclaturas que, em todos os domínios do conhecimento, ordenam os animais, as plantas, as rochas, os utensílios, os materiais, as cores, os astros e mesmo os deuses. Pois viver em sociedade não seria possível sem um mundo ordenado. Cada povo, por causa de sua história, de sua língua, de sua cultura e de seu ambiente, é único; assim, ele forja, detém e transmite às suas crianças uma visão de mundo sempre singular. Nicole Revel o explica soberbamente:

A imensa tentativa humana de explicar o universo não é mais que uma admirável e múltipla ilusão: aquela que tenta satisfazer uma aspiração metafísica e uma necessidade lógica, em uma busca sempre renovada de nomear, de explicar e de ordenar os objetos e os fenômenos presentes e ativos sobre essa terra, a fim de melhor dominá-los e de ter êxito na empreitada infinitamente complexa e necessária de viver em sociedade (Revel, 1990, p. 78).

O trabalho do etnólogo em uma dada população se volta, portanto, primeiro a tentar a catalogação deste acúmulo de saberes sobre o universo. Em seguida, a destacar as redes, as conexôes entre os diferentes campos desses conhecimentos cruzados. Dito de outra forma, compreender como funciona, na sincronia, esse tipo de capital-saber. Retomar, na diacronia, o desencadeamento que conduz a essa tela de fundo do conhecimento comum.

\section{Nomear para conhecer}

Tentemos compreender a atitude das pessoas que procuram nomear uma planta ou um animal. A sequência é a seguinte:
observar para descrever,
descrever para nomear,
nomear para conhecer,
conhecer não somente para utilizar,
mas também para pensar.

Para nomear, deve-se observar. Da observação, onde todos os sentidos são mobilizados, deriva uma descrição. Porém, como mostrou o linguista André Martinet (1970), "toda descrição supõe uma seleção" dentro da profusão dos critérios de descrição. Escolhemos, frequentemente sem perceber, somente alguns traços que podemos, então, designar como pertinentes. Vejamos alguns exemplos em diferentes línguas: 
238 | Françoise Grenand

Traços pertinentes simples

\begin{tabular}{|c|c|c|c|}
\hline \multicolumn{4}{|c|}{ odor } \\
\hline $\begin{array}{l}\text { wayampi², língua ameríndia, } \\
\text { família Tupi-Guarani (Guiana e } \\
\text { Brasil) }\end{array}$ & ïwitay & $\begin{array}{l}\text { tradução literal:"líber } \\
\text { apimentado" }\end{array}$ & $\begin{array}{l}\text { Annona amboyay } \\
\text { (ANNONACEAE) }\end{array}$ \\
\hline \multicolumn{4}{|c|}{ forma do fruto } \\
\hline $\begin{array}{l}\text { palikur, língua ameríndia, família } \\
\text { Aruwak (Guiana e Brasil) }\end{array}$ & bukutru-ateu & $\begin{array}{l}\text { tradução literal: "cabeça } \\
\text { de cutia" }\end{array}$ & $\begin{array}{l}\text { Licania sp. pl. } \\
\text { (CHRYSOBALANACEAE) }\end{array}$ \\
\hline \multicolumn{4}{|c|}{ textura da pele } \\
\hline $\begin{array}{l}\text { wayampi, língua ameríndia, } \\
\text { família Tupi-Guarani (Guiana e } \\
\text { Brasil) }\end{array}$ & kala & $\begin{array}{l}\text { tradução literal:" } \\
\text { [Pele] rugosa" }\end{array}$ & $\begin{array}{l}\text { Dioscorea trifida } \\
\text { (DIOSCOREACEAE) }\end{array}$ \\
\hline
\end{tabular}

Traços pertinentes complexos

\begin{tabular}{|l|l|l|l|}
\hline \multicolumn{4}{|c|}{ uma relação de comestibilidade real ou suposta com um animal } \\
\hline $\begin{array}{l}\text { língua crioula de } \\
\text { base francesa (Guiana) }\end{array}$ & papaye-biche & $\begin{array}{l}\text { tradução literal: "papaia do } \\
\text { veado vermelho” }\end{array}$ & $\begin{array}{l}\text { Ambelania acida } \\
\text { (APOCYNACEAE) }\end{array}$ \\
\hline \multicolumn{4}{|c|}{ em referência a uma entidade próxima já nomeada } \\
\hline francês & $\begin{array}{l}\text { carvalho peduncular (por } \\
\text { oposição a carvalho verde, } \\
\text { carvalho cortiça, séssil } \\
\text { carvalho, carvalho da } \\
\text { América...) }\end{array}$ & $\begin{array}{l}\text { Quercus robur } \\
\text { (FAGACEAE) }\end{array}$ \\
\hline chêne pédonculé & uma referência à mitologia & $\begin{array}{l}\text { Chenopodium ambrosioides } \\
\text { (CHENOPODIACEAE) }\end{array}$ \\
\hline português (Brasil) & erva-de-Santa-Maria & $\begin{array}{l}\text { Vismia cayennensis } \\
\text { (CLUSIACEAE) }\end{array}$ \\
\hline $\begin{array}{l}\text { um aspecto funcional } \\
\text { auluku, língua crioula de } \\
\text { base inglesa (Guiana) }\end{array}$ & pindia-udu & $\begin{array}{l}\text { tradução literal: “árvore } \\
\text { [para tratar de] dartro }\end{array}$ \\
\hline
\end{tabular}

\section{Nomear, logo classificar}

Para estabelecer sua nomenclatura, as populaçôes tradicionais consideram as coisas vivas não somente nelas mesmas, mas também na relação que elas elaboram com o que se assemelha a elas e com o que se diferencia delas, e com o que essas populaçóes irão fazer dessas coisas; é assim, como diz Buffon em sua Histoire Naturelle, no artigo Animais carniceiros (1758, tombo 7), "que se pode alcançar um conhecimento real" e "se elevar a um princípio geral”. E esse último ato, para a maioria das po- pulações tradicionais, se desenvolve na mitologia ou, melhor dizendo, no simbolismo, e não na evolução, pedra angular do princípio classificatório da ciência ocidental contemporânea. No domínio da fauna e da flora, em torno dessa mesma ideia de partida, da necessidade de agenciamento do vivente, seu eixo não é uma hierarquização integrada, mas o reconhecimento dos traços pertinentes de que falamos. É por isso que, muito frequentemente, as nomenclaturas nativas são multidimensionais. Elas recorrem aos critérios morfológicos, etológicos, edáficos, tecnológicos, mágicos..., para condu- 
zir ao conhecimento perfeito que deve servir ao Homem. É o célebre "Afinal, é preciso comer", do sábio proteiforme que foi Georges-André Haudricourt, que é necessário compreender no sentido mais amplo possível. Com efeito, esse conhecimento perfeito do ecossistema passa pela nominação e classificação, não somente do que se come, do que possui uma utilidade, mas também do que é venenoso, e mais ainda do que não se come, do que não serve para nada, do que se assemelha a uma coisa sem ser completamente idêntico a ela... Lévi-Strauss, em $L a$ Pensée Sauvage conclui com sabedoria:

[A partir de exemplos] que se poderiam tirar de todas as regióes do mundo, concluir-se-ia, de bom grado, que as espécies animais e vegetais não são conhecidas na medida em que sejam úteis; elas são classificadas úteis ou interessantes porque elas são primeiro conhecidas (LéviStrauss, 1962) ${ }^{3}$.

Individualizados, identificados segundo contornos eminentemente culturais, os objetos são, em seguida, segundo raciocínios também culturalmente marcados, ordenados em conjuntos superiores, pois nenhum espírito humano pode englobar, mesmo por associação de ideias ou por encadeamentos de traços pertinentes, toda a realidade do vivente e retêla. É necessário fazer, em algum momento, reagrupamentos, criar campos, fechar conjuntos. Por isso, vamos reter uma macrovariável, uma noção-chave. Esta poderá ser:

- os animais que vivem no ar (os mamíferos arborícolas e os pássaros),

- os animais de verão versus os animais de inverno (os que hibernam e os outros),

- os animais de pele versus os animais de escamas,

- as plantas de alagados,

- as plantas para atar (cipós), etc.
É, então, um fenômeno associativo que é posto em movimento, com um recentramento parcial, por patamar, em macrocategorias. Essas macrocategorias, que são os níveis superiores da nomenclatura indígena, não servem mais, propriamente falando, para identificar a espécie, mas para repartir o vivente. Elas servem, ensinou-nos Claude Lévi-Strauss (ibid.), para cogitar, especular, raciocinar, filosofar. Elas servem também para sonhar...

Na prática antropológica, ou seja, no exercício de nosso trabalho de campo cotidiano, observamos esses objetos, aos quais os membros de um povo deram um nome. Com sua ajuda, devemos encontrar em qual conjunto, baseado em qual tipo de raciocínio, essa palavra é posta junto ao objeto que ela representa. Os linguistas falam em isolar o par significante (a palavra) I significado (o objeto). Mas, a propósito, o que é um objeto? Tentemos esclarecer esse problema com a ajuda de dois pequenos exemplos. $\mathrm{O}$ primeiro será tomado de um domínio que nos toca de perto, pois que trata do corpo humano.

$\mathrm{O}$ peito. Todo mundo sabe o que é o peito. Ah, é? Onde ele começa? Onde termina? Até onde vai de alto a baixo, pelos lados? Será que ele é o mesmo em um homem e em uma mulher? E em uma criança? Cada povo terá sua visão e sua concepção do que é e do que não é o peito. De acordo com o recorte pelo qual terá optado, o nome, ou os nomes que lhe serão dados, simples ou compostos, são grandes as possibilidades deles conduzirem, uma vez traduzido em nosso sistema de nomenclatura, a uma perífrase definidora.

Segundo exemplo. Escolhamo-lo dessa vez na vastidão do cosmos. A constelação de Escorpiāo.

Não é todo mundo que conhece a constelação de Escorpião, mas numerosos são aqueles que a podem seguir com o dedo pela noite. Todos nós sabemos que seus contornos, sobre a abóbada celeste, ligam estrelas distantes mui- 
tos anos-luz zombando loucamente umas das outras. Essa construção alegórica, pois é isso que ela é, nós a herdamos da mitologia grega. Outros povos, em virtude de outras tradições míticas, elaboraram construções diferentes, às quais eles também deram nomes, retendo tal estrela, rejeitando outra.

Claude Lévi-Strauss, em Le cru et le cuit, (1964, p. 238-239) ${ }^{4}$, primeiro volume da sua coleção das Mitológicas ameríndias, explica-nos claramente ( $c f$. fig. 1) como: embaixo à esquerda, nosso Escorpiāo torna-se "Grande Serpente"; embaixo à direita, o Corvo vira a "Garça Voadora”; depois, no alto à esquerda, Hércules, despedaçado, toma os contornos do "Peixe Pacu", enquanto elementos do Vaqueiro se fazem "Piranha”, esses dois peixes enquadrando nossa Coroa Boreal, convertida em "Tatu”. Por fim, no alto à direita, nosso Leão, amputado de algumas estrelas, tomou o semblante de "Caranguejo".

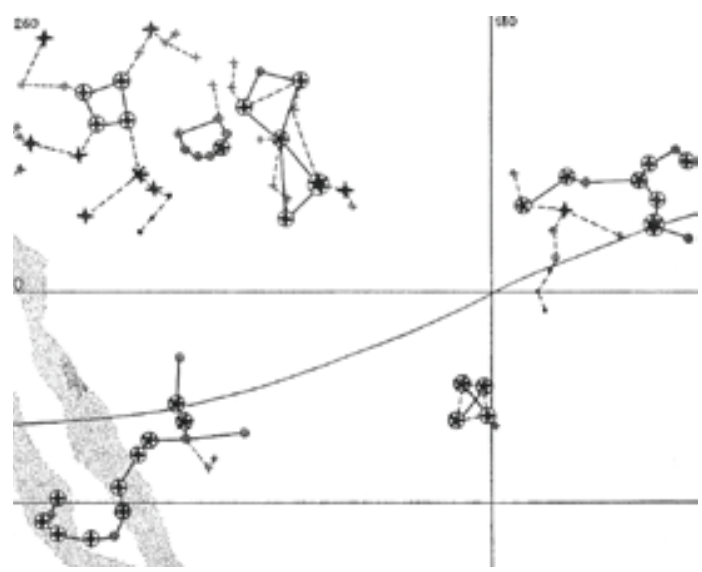

Fig 1 - Leitura diferencial das constelações segundo os Europeus e os Ameríndios. As constelações europeias estão na forma de estrelas interligadas por linhas pontilhadas. As constelações ameríndias estão na forma de estrelas inscritas em círculos e interligadas por traços inteiros. De Lévi-Strauss (1964, p. 238-239)5.

Eis o que me autoriza a escrever que, parte do corpo humano, constelação ou outra coisa, o objeto não é dado, mas criado através de um filtro cultural. Torna-se mais claro que o etnólogo é confrontado sem cessar, não com realidades intangíveis, mas com construções cognitivas? Essas construções se apoiam sobre o uso que é feito da língua por um pensamento, sempre singular, que distinguiu (segregou) cada um dos elementos do universo que o rodeia, para em seguida os amalgamar (agregar), para seu próprio uso.

\section{Classificaçóes Populares versus Taxonomia de Lineu}

Ao enfrentar constantes e excitantes problemas de contorno e determinação de objetos e, deste modo, de tradução e interpretação de palavras, o trabalho do pesquisador se desenrola no interior de um sistema de pensamento que, sob seus olhos, se formaliza mais a cada dia. Nesse caso se trata de um sistema diferente do seu e cujo código de acesso, frequentemente, ele (ainda) não possui. No que se refere à flora e à fauna, só depois de ter identificado os contornos de cada item é que ele se sentirá no direito de fazer a correspondência dos elementos e grupos que terão surgido àqueles do sistema científico, o latim atuando aqui como uma simples codificação, uma língua franca. As designações científicas, chegando ao final da cadeia, ganham então um inestimável valor, náo somente para codificar o sistema de pensamento indígena segundo as normas científicas ocidentais e poder falar dele mundo afora, mas também para permitir a comparação de diferentes sistemas entre si. Teremos compreendido que os binômios gênero + espécie não dizem mais do que eles podem e, sobretudo, que eles não substituem jamais um nome ou uma série de nomes vernaculares.

Uma ilustração das mais explícitas é fornecida pela classificação elaborada pelos Wayampi, para os seus grandes carnívoros (cf. fig. 2). Ela se apresenta como um sistema misto, a ser 
lido ora verticalmente, ora horizontalmente. Assim, Animais opostos às Plantas, Mamíferos aos Pássaros. Nos dois casos, se é, de maneira absoluta, um ou outro. Na leitura vertical: Animais na classe superior, depois Mamiferos imediatamente abaixo.

Isso deixa de valer quando abordamos os Mamiferos terrestres. Os Wayampi colocam a Ariranha ${ }^{6}$ nesta categoria quando, como escolhi seguir na figura 2 , se referem ao seu regime alimentar (a figura 2 sendo construída sobre os Mamíferos terrestres, só esse tipo de organização é visível). Mas eles não têm qualquer hesitação em colocá-la também entre os Mamiferos aquáticos, quando eles fazem referência a seus hábitos. Aqui a leitura torna-se horizontal, somos ora uma, ora outra, deslizamos de uma a outra em função das circunstâncias ( $c f$. um outro exemplo baseado na coloração, fig. 5).

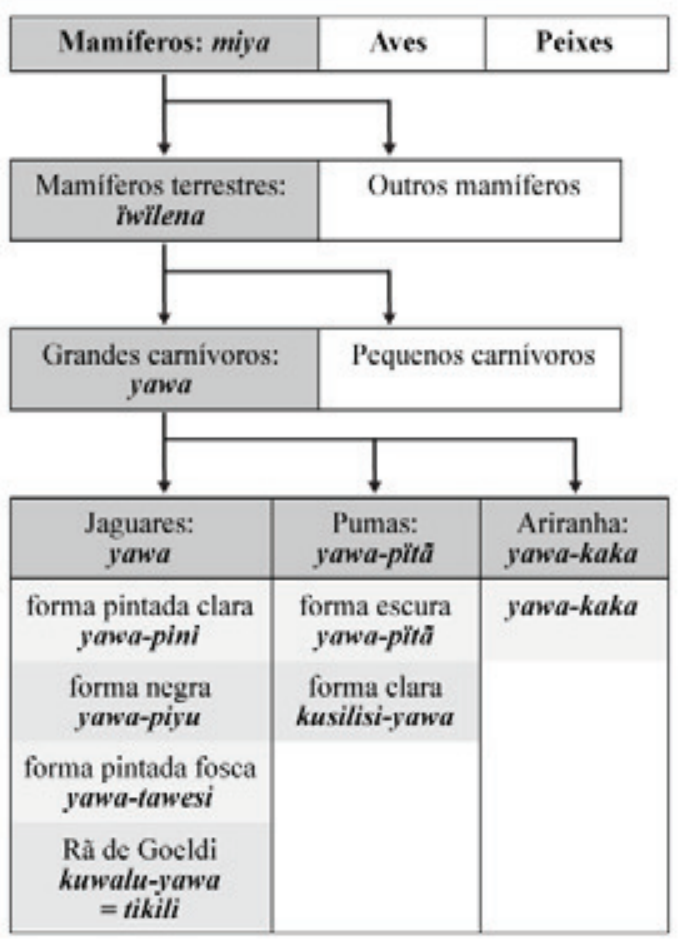

Fig 2 - Um exemplo de classificação dos grandes mamíferos: aquele dos Wayampi, ameríndios do Brasil e da Guiana.
Vemos em seguida que os Wayampi distinguem dois tipos de Puma só para a espécie Puma concolor, e quatro tipos de Jaguar onde a zoologia ocidental não vê mais do que a espécie Felis onca. Podemos mesmo ler, e não estamos lendo errado, que eles classificam como o quarto tipo de Jaguar a Rã de Goeldi. Para eles, como para uma boa parte dos povos ameríndios, essa rã é feiticeira. Ela pode, se assim o desejar, se metamorfosear em jaguar. E nesse caso, ela ruge, pois ela é um jaguar ( $c f$. fig. 3).

Esse pensamento simbólico tomando por base uma observação muito fina dos animais, não será surpresa constatar que a Rã exibe uma roupa das mesmas cores que o jaguar. Tampouco nos espantará que sob sua forma anfíbia os Wayampi a classifiquem entre os batráquios e, sob forma felina, entre os felídeos.
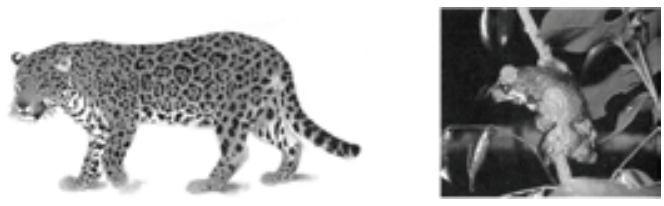

Fig 3 - A Rã de Goeldi, sob sua forma de batráquio e sob sua forma de felino, segundo os Wayampi (desenho de Fr. Feer, in Emmons L. H.; Feer F. Neotropical Rainforest Mammals: a Field Guide. Chicago: The University of Chicago Press, 1990. Foto: Ch. Marty, 2000).

Cada uma das classificações indígenas comporta, como já havia dito, traços singulares, aliás, mais e mais numerosos gradativamente e à medida que se mergulha nos detalhes do vivente. No que diz respeito às grandes categorias, de fato, elas procedem muito frequentemente de grandes correntes de pensamento, cujos meandros e redemoinhos os antropólogos podem seguir de uma área linguístico-cultural a outra. Por exemplo, os Guarani-Izoceños, da mesma família Tupi-Guarani que os Wayampi, mas que estão a vários milhares de quilômetros de distância (Chaco boliviano), escolhe- 
ram também o habitat como principal critério distintivo dos animais. Assim, eles falam dos peixes como animais aquáticos, dos pássaros como animais aéreos e dos quadrúpedes como animais terrestres, mas certos lagartos, apesar de suas quatro patas, serão pensados primeiramente como animais aéreos por seu hábito arborícola (Combès, 2003).

A classificação dos grandes mamíferos (cf. fig. 2) vai nos ajudar a abordar uma outra questâo. Crê-se frequentemente universal a noção de nominação do gênero por um monômio em relação àquela da espécie, que seria um binômio compreendendo o nome do gênero. É verdade, como pensam geralmente os cognitivistas, os linguistas e os antropólogos, que todo sistema de classificação, para ser performativo, deve estar a serviço da memória.

Nesse sentido, ele deve funcionar de maneira econômica. E formar, como a ciência ocidental está acostumada, o nome da espécie em relação àquele de seu gênero é, sem dúvida, um achado de gênio. Em uma obra de referência sobre a questão, Brent Berlin (1992) não falhou em sublinhar que a ideia ocorreu a numerosos povos. Mas é somente na taxonomia de Lineu que ela assume o papel de dogma intransgressível. Em todos os outros lugares ela sofre sem danos múltiplas licenças, como mostra o exemplo dos Wayampi e de seus grandes mamíferos. O termo yawa, "carnívoro", do qual o francês tirou a sua palavra jaguar, se encontra primeiro, no nível que os taxonomistas chamariam de "Família”. Reencontramo-lo, intocado, no nível que equivaleria ao "Gênero". Aquele correspondente a "Espécie", em sua grande maioria, o mostra bem. Mas a forma teratológica do jaguar possui dois nomes, dos quais um é simples. Quanto ao "Gênero" puma, yawa-pïtã, já sob a forma de um binômio, ele não é senão o nome que reencontramos no nível inferior para a "Espécie".

Brent Berlin nos oferece outro exemplo, aquele da classificação das pombas por um ou- tro povo ameríndio, os Huambisa do Peru. Ele nos mostra $^{7}$ que as seis espécies latinas, ainda que classificadas em uma mesma "Família", se repartem em seguida em quatro "Gêneros" não nomeados de uma "Espécie" cada, e um quinto "Gênero" que compreende duas "Espécies”. Vêse que o nome da "Família" é também o de um "Gênero" e de uma "Espécie". Enfim, quatro "Espécies" levam um nome simples.É preciso notar que, ainda que o sistema de nomenclatura indígena e o sistema taxonômico que ainda usa a nomenclatura de Lineu tenham ambos pretensões globalizantes e cosmogônicas, o sistema científico, fruto do movimento de ideias sobre a evolução no pensamento ocidental, tem fundamentos culturais, em particular universalistas, abertamente diferentes. Adotando um ponto de vista essencialmente hierárquico, ele privilegia arbitrariamente e quase exclusivamente (pelo menos na afirmação do princípio, se não na realidade), o critério de reprodução sexuada. Lembramo-nos então do gracejo que Haudricourt lançava algumas vezes nas suas aulas: "A botânica é a etnobotânica dos botânicos". Ressituada na trajetória geral das ideias no Ocidente, a história cultural da taxonomia, com os enfrentamentos dos estudiosos que a marcam, e cujo eco se encontrará em certas páginas dessa obra não o desmentiria.

\section{As Armadilhas da Nomenclatura}

São numerosas as armadilhas nas quais o etnólogo arrisca cair durante seu trabalho de codificação da nomenclatura indígena em direção à taxonomia científica. Vejamos alguns exemplos.

As categorias podem ser:

- explícitas, isto é, nomeadas. É difícil encontrar línguas que náo reagrupariam quase todos os peixes em uma caixa com essa bela etiqueta: "Peixes"; 
- implícitas, isto é, latentes, não-nomeadas, como são chamadas desde Conklin (1962). Por isso, essas são frequentemente as mais difíceis de perceber. É assim que os Wayampi, povo Ameríndio da Guiana Francesa e do Brasil, reúnem em uma macrocategoria todas as palmeiras que reconhecem. Mas essa caixa não é etiquetada. Recorrendo à mesma metáfora, poderíamos dizer que a caixa é transparente e que essa transparência é suficiente para que se reconheça seu conteúdo. Dito de outra forma, sua língua não possui palavra que possamos traduzir por "Palmeira". No entanto, quando trabalhamos com eles, eles organizam muito conscienciosamente todas as palmeiras, mesmo as espécies trepadeiras, na mesma categoria.

Poderá haver caixas quase vazias: por exemplo, as borboletas, e entre elas algumas que qualificaríamos sem hesitar como notáveis, não terão todas um nome, e numerosas espécies, distinguidas sem serem especificamente nomeadas, serão simplesmente arranjadas na caixa devidamente rotulada como "borboletas".

Encontraremos também caixas muito compactas, recobrindo quase integralmente a realidade das formas vivas: é assim que os Wayampi distinguem e dão um nome diferente a cada batráquio que vive em torno deles. Somente duas espécies, as quais os batraquiólogos qualificam como simpátricas, são recobertas por uma denominação única (Grenand et alii, 1980).

Enfim, teremos compreendido que as categorias são frequentemente encaixadas. Isso significa que um certo critério adotado orientará o item para certa caixa num dado momento, e que um segundo critério orientá-lo-á para outra caixa no instante seguinte. Ainda entre os Wayampi, isso resulta aproximadamente no seguinte: o macaco sagui de mão ruiva, kusili (Saguinus midas) é classificado na mesma caixa que o roedor cutia, akusi (Dasyprocta aguti) quando nos atemos à morfologia (o vermelho da roupa marcado pelo mesmo componente kusi nos dois nomes) como critério de seleção. Eles são colocados em duas caixas diferentes se nos ativermos agora a um critério etológico, o do espaço de mobilidade.

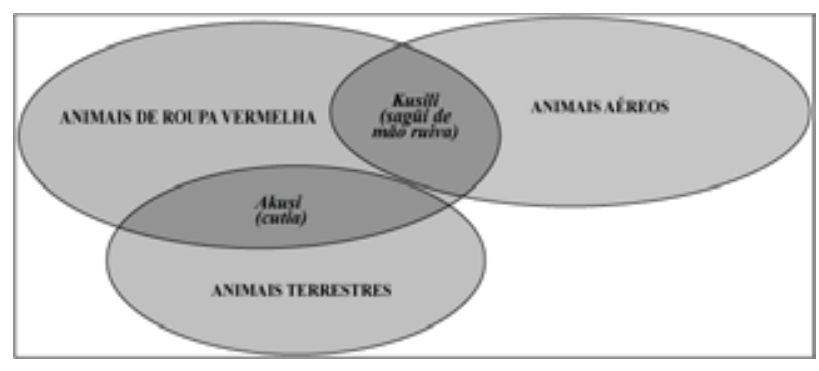

Fig 5 - Exemplo de classificação encaixada entre os Wayampi. A cutia, Dasprocta agouti; o sagui de mão ruiva, Saguinus Midas.

As caixas estão uma ao lado da outra, não uma acima da outra, nem uma na outra: não estamos no domínio da hierarquização. Isso significa que poderemos passar dos animais de roupa vermelha aéreos aos animais aéreos de roupa vermelha; segundo o ponto de vista que nós selecionarmos, isso não terá o mesmo valor.

Por mais que o esperemos, o recorte com o qual nos deparamos é em geral tão diferente daquele ao qual fomos habituados desde nossa infância ocidental, que as derrapagens são frequentes, assim como os casos de cegueira. Ter espírito científico não é garantia contra o etnocentrismo. Assim, uma nomenclatura mais ligeira do que a nossa, será pensada pobre e não simples; se ela é mais pesada, pensaremos que ela é enganosa (em relação à taxonomia de Lineu) e não rica. Tomaremos então cuidado antes de empregá-las, ao definir palavras como subclassificação ou sobreclassificação em função de seu valor no interior do sistema em questão, e não em comparação com o nosso. 


\section{Vocabulário-reflexo}

As riquezas do ecossistema e as maneiras como elas são percebidas conduzem, em cada cultura humana, à elaboração de um sistema de valores próprio a cada uma; ele é feito para ela e por ela, ele é único. Isso se refletirá naturalmente no léxico. É por isso que o linguista norte americano Edward Sapir (1921) fala tão lindamente em vocabulário reflexo. As variaçōes da realidade vão, ipso facto, fazer variar o léxico botânico e zoológico de um povo a outro. Alguns exemplos são óbvios.

Chamemo-los exemplos positivos:

- o arroz, cereal de base para numerosos povos asiáticos, dá lugar em suas línguas a uma profusão de termos;

- o universo branco de neve entre os Inuit fez nascer em suas diferentes línguas mais de cem palavras diferentes para os diversos tipos de gelo;

- a importância econômica do coco entre os Tahitianos os conduziu a uma extraordinária riqueza em termos concernentes a todos os aspectos (botânico, econômico, cultural, metafórico...) ligados a essa palmeira mais que a qualquer outra planta;

- o muito refinado conhecimento que os Pigmeus têm do elefante é reencontrado em seu vocabulário, onde eles detalham com infinito prazer esse gigante de seu universo;

- enfim, a tradição da caça com cachorro no Ocidente nos gratifica com uma notável inflação dos termos em torno dos cervídeos, não somente em sua morfologia, mas na arte de sua caça.

Existem exemplos negativos, "por falta de referente" nos diz Denise François-Geiger (1990), que se compreendem tão facilmente quanto:

- os povos da floresta, sem horizonte, nem grandes espaços, têm pouco desenvolvido o vocabulário astronômico ou aquele relativo aos ventos;

- não nos surpreenderá a ausência de um vocabu- lário "neve-gelo-geada" para um povo tropical, nem de um vocabulário marinho para um povo da floresta.

Os exemplos negativos, agora por excesso, são mais difíceis de apreender:

- numerosas populaçóes ameríndias não têm sentido necessidade de inventar uma palavra para a cor "verde". Imersas que elas são em uma paleta de verdes, o verde é uma cor dada, primordial, e são as outras que elas têm necessidade de nomear;

- da mesma maneira, os povos essencialmente caçadores não têm palavra para nosso simples "caçar". Considerado como trivial e, no mais, excessivamente banal, não suficientemente conotado, desprovido de sentido em suma, ele é substituído pelo detalhe de todas as técnicas de caça: caça a espreita no solo, caça a espreita nas árvores, caça a frente de si, caça com rede, caça com arco, caça com espingarda, caça com pios, caça com montaria, caça solitária, caça diária, caça em expedição longínqua...

Enfim, encontramos algumas vezes exemplos em positivo-relíquia.

Essas relíquias lexicais, esses traços fossilizados no léxico são constituídos de palavras isoladas na realidade presente e se referem a uma realidade outra, mais antiga. Elas servirão, entáo, ao pesquisador como nexo, por exemplo, para explicitar o caminho de uma antiga migração.

- É assim que os Wayampi, povo eminentemente florestal, conservam no estado de traços os resquícios de um vocabulário marinho, que se refere ao Oceano Atlântico e ao Amazonas, presente em seus cantos e mitos;

- quanto aos Aluku, povo quilombola, eles conservaram de sua longínqua África até no Suriname e depois na Guiana Francesa, a memória do ele- 
fante, com um nome e uma descrição mitificada;

- poderemos, também, encontrar entre povos sem agricultura alguns resquícios de um vocabulário agrícola: esse é o caso dos Akulio do Brasil e do Suriname, que as perturbaçôes que se seguiram à conquista da América do Sul forçaram a um nomadismo radical; poderemos, ademais, citar o caso de povos agricultores sedentários antes $\mathrm{da}$ desertificação da África, que, depois, se tornaram pastores nômades.

Esses exemplos, verdadeiros elos para compreender que situaçóes contemporâneas podem ser náo mais do que evoluçóes regressivas, nos mostram também que os estados sucessivos de caça-coleta-pecuária-agricultura, ainda frequentemente considerados como etapas obrigatórias da evolução do Homem, são uma visão do espírito desmentida pelos fatos.

\section{As palavras que viajam}

Eis o que nos introduz na viagem das palavras. Por ocasião de uma migração, um povo leva com ele um tesouro lábil, frágil, impalpá- vel: sua língua. À medida que mudam as paisagens, mudam também as realidades a nomear (Grenand, 1995a, 1995b). É assim que certas palavras se tornam, literalmente, palavras vazias de sentido (os linguistas falam de significante sem significado), enquanto que novas entidades têm a necessidade de ser nomeadas. Tornase, então, tentador se servir dessas cascas vazias que são as palavras que não se referem mais a qualquer realidade concreta, para vestir de um nome os novos objetos. A propósito desses novos objetos, ainda não-nomeados, os linguistas falam desta vez de significado sem significante. Percebemos que é escolhendo um traço semântico pertinente para o povo em questáo, que se selecionará um termo do estoque lexical $\mathrm{A}$, tornado obsoleto, para nomear uma realidade nova, tornando-se, assim, um termo reavivado do estoque lexical B. Eis aqui um exemplo ( $c f$. fig. 6).

Os Wayampi, hoje nas Guianas, conviveram outrora, no sul do Rio Amazonas, com a espécie de árvore Trichilia lecointii (presente na Lingua Geral sob a forma parakauba). Atualmente, os mesmos Wayampi nomeiam palaku’̈ (para linguistas se trata de uma evolu-
Fig 6 - Exemplo de troca de objeto por uma mesma palavra.
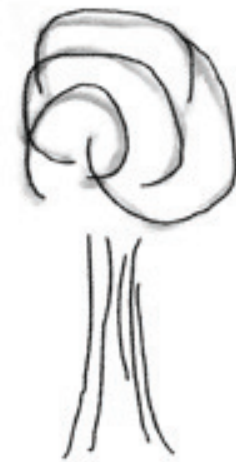

Trichilia lecointii MELIACEAE: parakauba ESTOQUE LEXICAL A

significante perdendo seu significade

TRACOS DE. SENTIDO RETIDO: ánere em que se tatalham remos 
ção fonética simples) a espécie Aspidosperma marcgravianum. Para além da dessemelhança manifesta entre as duas árvores (a primeira é uma Meliacea, a segunda uma Apocynacea), o traço semântico retido foram as longas pregas do tronco, nas quais, tendo perdido a primeira espécie em proveito da segunda, eles podem, todavia, continuar a entalhar seus remos.

\section{E o lugar do Homem nisso tudo?}

Os povos amazônicos têm diversas opinióes sobre essa questão essencial. Para alguns, tais como os Araweté do Brasil, os homens são deuses, decaídos sim, porém deuses ${ }^{8}$. Para outros, e falaremos uma última vez dos Wayampi, o Homem é um animal. E a mitologia está ali para lembrá-los disso. Três mundos, três discos de terra se sobrepóem no cosmos ( $c f$. fig. 7). Sob o mundo superior, ocupado pelos urubus de duas cabeças, o mundo dos Humanos ocupa uma posição central. Ele é coberto pela grande floresta, na qual são abertas as clareiras para as roças e para as aldeias; ele é clareado alternadamente por duas entidades masculinas: Sol, Kwalä̈ e Lua, Yä̈. Sobre uma margem do mundo existe uma árvore gigante, na qual é preciso trepar para alcançar, na ramificação principal dos galhos, uma abertura, início de um gigantesco tobogã dando diretamente no mundo de baixo.

Abaixo, pois, desembocamos no mundo ctoniano, clareado pelos mesmos Sol e Lua embarcados em curso eterno. Dito de outra forma, quando se faz noite no nosso mundo, faz-se dia embaixo. Esse mundo, também ele coberto pela grande floresta, é habitado por seres fabulosos: os woo. Os homens, frequentemente xamãs, que se arriscaram a encontrálos, assimilam-nos como Preguiças gigantes e canibais.
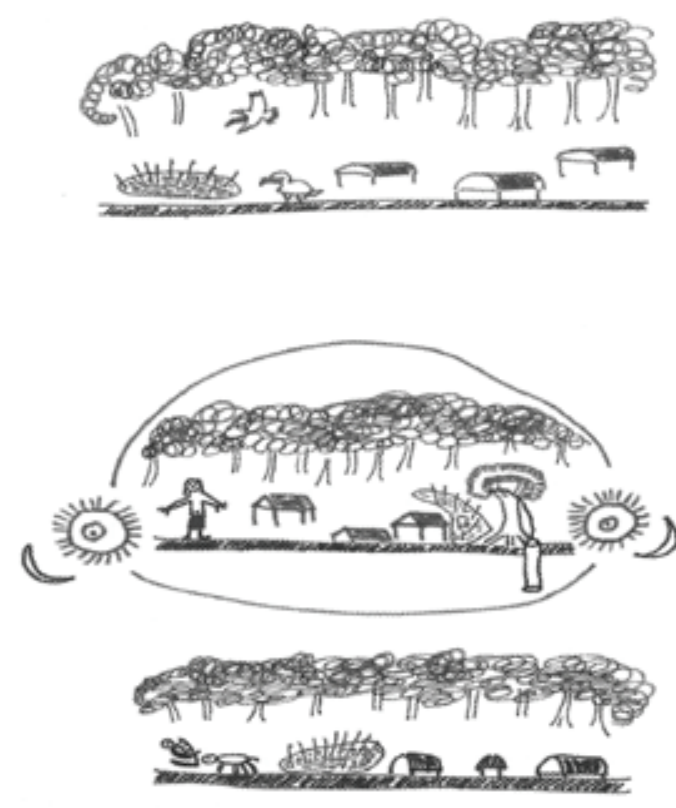

Fig 7 - 0s três mundos superpostos dos Wayampi. Em cima, 0 mundo dos Urubus de duas cabeças, mestres da podridão; no meio, o mundo dos Homens com o túnel de passagem para 0 terceiro mundo, o mundo de baixo, habitado pelas Preguiças gigantes canibais (de um desenho de Alasuka, in Grenand, 1982).

Esses mesmos monstros qualificam os Homens, suas presas potenciais, de Juparás ${ }^{9}$. Eles matam os adultos e fazem de seus pequenos, as crianças, animais domésticos para sua própria progenitura. Aliás, assim fazem os Homens com os pequenos macacos quando eles matam uma mãe em uma caçada. Dito de outro modo, rebaixando-os ao nível da caça e do animal de companhia, as Preguiças gigantes tiram aos Homens a sua qualidade de humanos e não lhes deixam outra alternativa que a de serem animais, obrigando-os a uma sábia e salutar humildade: ser Homem não é mais que um dado subjetivo, subordinado ao olhar daquele que lhe avalia, animal ou homem.

Enfim, eu não resisto a provocar nossas consciências acrescentando que o Homem, nas Américas, provavelmente tenha sido contemporâneo do Mylodon (Megatherium sp.), uma 
preguiça gigante (Ramirez Rozzi et alii, 2000). Sua extinção pode ter sido transmutada pelo pensamento mítico em uma descida ao mundo subterrâneo.

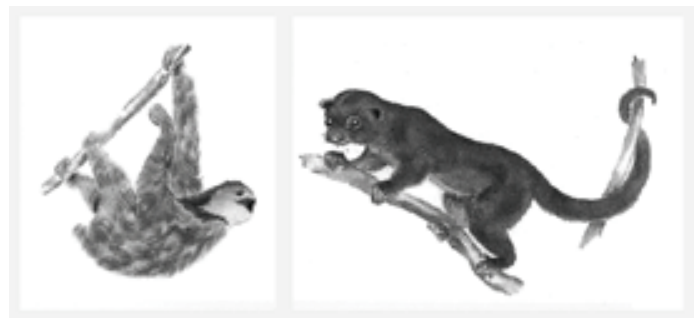

Fig 8 - À esquerda, a preguiça de três dedos (Bradypus tridactylus) é, para os Wayampi, um animal bastante próximo dos wo'o, preguiças gigantes e canibais que povoam o mundo de baixo. Esses últimos veem o Homem sob os traços do Jupará (Potos flavus), à direita. Dito de outra forma, Homem, Animal ou Monstro, não é mais que uma questão de ponto de vista e, portanto de cultura (Desenhos de F. Feer in Emmons L. H.; Feer F. Neotropical Rainforest Mammals, a Field Guide. Chicago: The University of (hicago Press, 1990).

\section{Conclusão}

Ela se impóe por si só. É a noção de ponto de vista que se mostra essencial. Eu já havia dito: o objeto não é dado, ele é criado; criado por um ponto de vista, validado por uma lógica específica. Eis porque, se nos ativermos às noções de classificação, será totalmente ilusório esperar que a nomenclatura latina recubra sem problema, sem vazio nem inchaço, a nomenclatura indígena. Cada nome indígena não pode possuir, ipso facto, um correspondente latino imediatamente identificável, simplesmente porque não possuem o mesmo ponto de vista. É aqui que Lévi-Strauss conclui:

[...] há duas formas distintas de pensamento científico, ambas função, não certamente de estágios desiguais de desenvolvimento do espírito humano, mas de dois níveis estratégicos onde a natureza se deixa atacar pelo conhecimento científico: um aproximativamente ajustado ao da percepção e da imaginação, e outro sem apoio; como se as relaçóes necessárias, objetivo de toda ciência - seja ela neolítica ou moderna - pudessem ser atingidas por dois caminhos diferentes: um muito perto da intuição sensível e outro mais afastado (Lévi-Strauss, 1962, p. 28) ${ }^{10}$.

O universo das ideias de Platão deixa filtrar aquela concepção segundo a qual as espécies preexistem. Aristóteles, apesar de ser seu aluno, pensa exatamente o contrário: as espécies são criações do espírito. Epicteto, em seu Manual, acrescenta: "O que move os homens, não é a coisa por ela mesma, mas a ideia que eles fazem dela”. E desde então, o pensamento ocidental oscila entre os dois, ainda que Aristóteles pareça ter a vantagem (Lercher, 1985). Será que a espécie existe fora da sociedade que a isola? O nome latino nos leva a crer que a planta ou o animal que está diante de nós é uma realidade científica. Dizse que "as espécies são objetos naturais, não produtos do espírito". Ao mesmo tempo, sabemos bem que os termos vernaculares são criaçóes humanas carregadas de sentido. Há mais de trinta anos, Marie Martin (1974) já disse que as espécies botânicas, mesmo assim definidas através de uma linguagem extinta e supostamente neutra, o latim, permanecem ainda o produto de uma reflexão classificatória, fruto do cérebro humano. Sem dúvida esse esforço procurou se aproximar de uma ordem entendida pelos botânicos como natural, mas as querelas entre taxonomistas aí estão para nos provar que o natural flutua ao capricho dos modos, das regióes, dos tempos, e que ele é, assim, questão de cultura. Como entre os Wayampi, portanto...

Cada sistema é e continua único, criado por uma sociedade para seu próprio uso, na me- 
dida de sua própria história e de sua visão de mundo.

Face aos mil e um sistemas nos quais as sociedades tentam conter o universo que as rodeia, esbarramos no problema da classificação do vivente. Sem dúvida, no fim das contas, assim como para essa unidade emblemática que é a espécie, é mais sábio concluir que cada solução é válida apenas na cultura que, em dado momento e lugar, a isola.

Da Renascença ao século XVIII, os monstros e os... anjos fizeram parte dos livros de zoologia, seja para afirmar sua existência, seja para dela duvidar.

Perguntamo-nos francamente em nome de quê os Wayampi renunciariam a ver sob a forma de um Jaguar a metamorfose de uma Rã...

\section{Notas}

1 Françoise Grenand é pesquisadora do Centre National de la Recherche Scientifique (CNRS) em Caiena, Guiana Francesa.

2 N. T. O grupo Wayampi ou Wajāpi (como é grafado no Brasil) ocupa as regiôes das bacias dos rios Amapari e Jari no estado do Amapá (Brasil) e a cabeceira do rio Oiapoque na Guiana Francesa. Como o trabalho de campo da autora foi realizado nos Wayampi da Guiana, optamos por deixar a grafia do etnônimo desse grupo tal como a autora o escreve, justamente para marcar as diferenças que existem entre os grupos que ocupam os dois lados da fronteira.

3 N. T. Edição brasileira: LÉVI-STRAUSS, Claude. $O$ Pensamento Selvagem. Tradução de Maria Celeste da Costa e Souza e Almir de Oliveira Aguiar. São Paulo: Companhia Editora Nacional. 1970, p. 29.

4 N. T. Edição brasileira: LÉVI-STRAUSS, Claude. $O$ cru e o cozido. Tradução de Beatriz Perrone-Moisés. São Paulo: Cosac \& Naify, 2004, p. 268-269 (Mitológicas, 1).

5 N. T. Ibid.

$6 \quad$ N. T. Pteronura brasiliensis.

7 N. E. Figura 4: desenho ilustrando a classificação das pombas entre os Huambisa do Peru (Berlin, 1992, p. 140). Reprodução não autorizada.
8 N. T. A autora se refere aqui a Viveiros de Castro (1986).

9 N. T. Potos flavus, são mamíferos arborícolas da mesma família do Quati.

10 N. T. Edição brasileira: LÉVI-STRAUSS, 1970, Op. cit., p. 36.

\section{Referências Bibliográficas}

BERLIN, Brent. Ethnobiological Classification, Principles of Categorisation of Plants and Animals in Traditional Societies. Princeton: Princeton University Press, 1992.

BUFFON, Georges-Louis; LECLERC, comte de. Histoire naturelle, générale et particulière, avec la description du Cabinet du Roy. Paris: Imprimerie Royale, 1758, tomo 7.

COMBÈS, Isabelle. Aproximación a la clasificación guaraní de los animales. In: CUÉLLAR, Erika; NOSS, Andrew (eds.). Mamiferos del Chaco y de la Chiquitania de Santa Cruz, Bolivia. Santa Cruz: ed. FAN, 2003 , p. $1-8$.

CONKLIN, H. C. The Lexicographical Treatment of Folk Taxonomy. International Journal of American Linguistics, vol. 28, p. 119-141, 1962.

FRANÇOIS-GEIGER, Denise. À la recherche du sens: des ressources linguistiques aux fonctionnements langagiers (numéro spécial 22). Paris: Peeters-SELAF, 1990.

GRENAND, Françoise. Et l'homme devint jaguar: univers imaginaire et quotidien des Indiens Wayãpi. Paris: L'Harmattan, 1982.

GRENAND, Françoise. Le voyage des mots, logique de la nomination des plantes : exemples dans les langues tupi du Brésil. Cahiers du Lacito, Revue d'ethnolinguistique, n. 7, p. 23-42, 1995.

GRENAND, Françoise. Nommer la nature dans un contexte prélinnéen : les Européens face aux Tupi, du $\mathrm{XVI}^{\mathrm{e}}$ à la première moitié du XVII ${ }^{\mathrm{e}}$ siècle. Amerindia, n. 19-20, p. 15-28, 1995.

GRENAND, Pierre; GRENAND, Françoise; LESCURE, Jean. Les amphibiens dans l'univers wayãpi. JATBA, 27 (3- 4), p. 247-261, 1980.

EMMONS, L. H.; FREER, F. Neotropical Rainforest Mammals, a Field Guide. Chicago: The University of Chicago Press, 1990.

EPICTÈTE. Manuel. Paris: Nathan, 1998.

LERCHER, Alain. Les mots de la philosophie. Paris: Belin, 1985.

LESCURE, Jean; MARTY, Christian. Atlas des Amphibiens de Guyane. Paris: Muséum National d'Histoire Naturelle (MNHN), 2000. 
Nomear SeU UnIVERso: Por QUÊ? Como? 249

LÉVI-STRAUSS, Claude. La Pensée Sauvage. Paris: Plon, 1962.

LÉVI-STRAUSS, Claude. Le cru et le cuit. Paris: Plon, 1964 (Mythologiques, 1).

MARTIN, Marie. Essai d'ethnophytogéographie khmère. JATBA, 21 (7-8-9), p. 219-337, 1974.

MARTINET, André. Eléments de linguistique générale. Paris: Armand Colin, 1970.

REVEL, Nicole. Les dons de Nägsalad. Paris: Peeters-SELAF, 1990 (Fleurs de paroles, histoire naturelle palawan, 1).

RAMIREZ ROZZI, F. V.; ERRICO, F. d. ; ZARATA, M. Le site paléo-indien de Piedra Museo (Patagonie), sa contribution au débat sur le premier peuplement du continent américain. In: Compte rendus de l'Académie des Sciences - Série IIA, Earth and planetary Science, vol. 331 (4), p. 311-318, 2000.
SAPIR, Edward [1921]. Le langage. Introduction à l'étude de la parole. Paris: Petite Bibliothèque Payot, 1970.

VIVEIROS DE CASTRO, Eduardo. Araveté: os deuses canibais. Rio de Janeiro: Jorge Zahar / ANPOCS, 1986.

\section{Agradecimentos}

Oferecemos nossos agradecimentos pela realização desta tradução às Editions Belin, assim como a The University of Chicago Press e Christian Marty pela gentil disponibilização de suas imagens. Também somos agradecidos pelos conselhos acurados de Dafran Macário.

\section{traduzido de}

GRENAND, Françoise. Nommer son univers: Pourquoi? Comment? Exemples parmi des sociétés amazoniennes. In: PRAT, D.; RAYNAL-ROQUES, A. ; ROGUENANT, A. (eds.). Peut-on classer le vivant? Linné et la systématique aujourd'hui. Paris: Belin, 2008, p. 119-130.

\section{tradutora Joana Cabral de Oliveira}

Doutoranda em Ciência Social (Antropologia Social)/USP

revisora Luísa Valentini

Mestranda em Ciência Social (Antropologia Social)/USP

revisor Nicodème de Renesse

Mestrando em Ciência Social (Antropologia Social)/USP

Recebida em 23/03/2009

Aceita para publicação em 08/09/2009 